\title{
Supplementary of
}

\section{Impact of biomass burning aerosols on radiation, clouds, and precipitation over the Amazon during the dry season: dependence of aerosol-cloud and aerosol-radiation interactions on aerosol loading}

Lixia Liu ${ }^{1}$, Yafang Cheng ${ }^{1}$, Siwen Wang ${ }^{1}$, Chao Wei ${ }^{1}$, Mira Pöhlker ${ }^{1}$, Christopher Pöhlker ${ }^{1}$, Paulo

Artaxo $^{2}$, Manish Shrivastava ${ }^{3}$, Meinrat O. Andreae ${ }^{1,4}$, Ulrich Pöschl ${ }^{1}$ and Hang Su${ }^{1}$

${ }^{1}$ Max Planck Institute for Chemistry, Mainz, Germany

${ }^{2}$ Institute of Physics, University of São Paulo, São Paulo 05508-900, Brazil

${ }^{3}$ Pacific Northwest National Laboratory, Richland, Washington, USA

${ }^{4}$ Scripps Institution of Oceanography, University of California at San Diego, La Jolla, California, USA

Correspondence to: yafang.cheng@mpic.de\&h.su@mpic.de 
Table S1. Estimates of radiative perturbation by biomass burning aerosols over the Amazon Basin in this study and from previous studies.

\begin{tabular}{|c|c|c|c|c|c|c|c|}
\hline & Description & 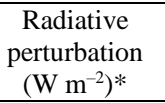 & AOD & Effect & $\begin{array}{c}\text { Region of } \\
\text { Amazon } \\
\text { Basin }\end{array}$ & Model & Reference \\
\hline \multirow[t]{3}{*}{ Clear-sky } & SW at TOA & $-5.6 \pm 1.7$ & $0.25 \pm 0.11$ & ARI & Southern & SBDART & Sena et al. (2013) \\
\hline & $\mathrm{SW}$ at TOA & $-3.33 \pm 0.89$ & 0.67 & total & Southern & HadGEM3-GA3 & Thornhill et al. (2018) \\
\hline & SW at TOA & {$[-0.7,-3.7]$} & $0.2-0.6$ & ARI & Central & WRF-Chem & This study \\
\hline \multirow[t]{8}{*}{ All-sky } & $\begin{array}{l}\text { SW at TOA } \\
\mathrm{LW} \text { at TOA } \\
\text { SW at surface }\end{array}$ & $\begin{array}{r}1.35 \pm 1.8 \\
-3.07 \pm 1.55 \\
-5.46 \pm 1.93\end{array}$ & 0.67 & total & Southern & HadGEM3-GA3 & Thornhill et al. (2018) \\
\hline & $\mathrm{SW}$ at TOA & $\begin{array}{r}-1.75 \\
2.72 \\
1.53 \\
\end{array}$ & $\begin{array}{l}0.8-1.2 \\
0.4-1.0 \\
0.4-1.0\end{array}$ & ARI & Southwest & WRF-Chem & $\begin{array}{l}\text { Archer-Nicholls et al. } \\
\text { (2016) }\end{array}$ \\
\hline & $\begin{array}{l}\mathrm{SW}+\mathrm{LW} \text { at TOA } \\
\mathrm{SW}+\mathrm{LW} \text { at surface }\end{array}$ & $\begin{array}{l}-4 \pm 1 \\
-9 \pm 1\end{array}$ & & ARI & Southern & MetUM & Kolusu et al. (2015) \\
\hline & $\begin{array}{l}\mathrm{LW} \text { at TOA } \\
\text { SW at surface }\end{array}$ & $\begin{array}{l}-0.12 \\
-15.9\end{array}$ & & total & entire & WRF-Chem & Wu et al. (2011) \\
\hline & $\begin{array}{l}\text { SW at surface } \\
\text { LW at surface }\end{array}$ & $\begin{array}{r}-28.23 \\
8.6\end{array}$ & 0.633 & total & Southern & GATOR-GCMOM & Ten Hoeve et al. (2012) \\
\hline & SW at surface & -10 & $0.2-0.4$ & ARI & Northwest & CCATT-BRAMS & Rosario et al. (2013) \\
\hline & $\begin{array}{l}\text { SW at TOA } \\
\text { LW at TOA } \\
\text { SW at surface } \\
\text { LW at surface }\end{array}$ & $\begin{array}{r}{[-0.3,0.6]} \\
{[0.1,0.9]} \\
{[-6.7,-31.8]} \\
{[0.3,1.9]} \\
\end{array}$ & $0.2-0.6$ & total & Central & WRF-Chem & This study \\
\hline & $\begin{array}{l}\text { SW at TOA } \\
\text { LW at TOA } \\
\text { SW at surface } \\
\text { LW at surface }\end{array}$ & $\begin{array}{r}0.4,2.0] \\
{[0.1,1.0]} \\
{[-5.7,-30.5]} \\
{[0.4,2.0]} \\
\end{array}$ & $0.2-0.6$ & ARI & Central & WRF-Chem & This study \\
\hline
\end{tabular}

*Radiative perturbation with standard deviation or in bracket for range obtained from simulations with emission intensity of EMIS1-EMIS6. 


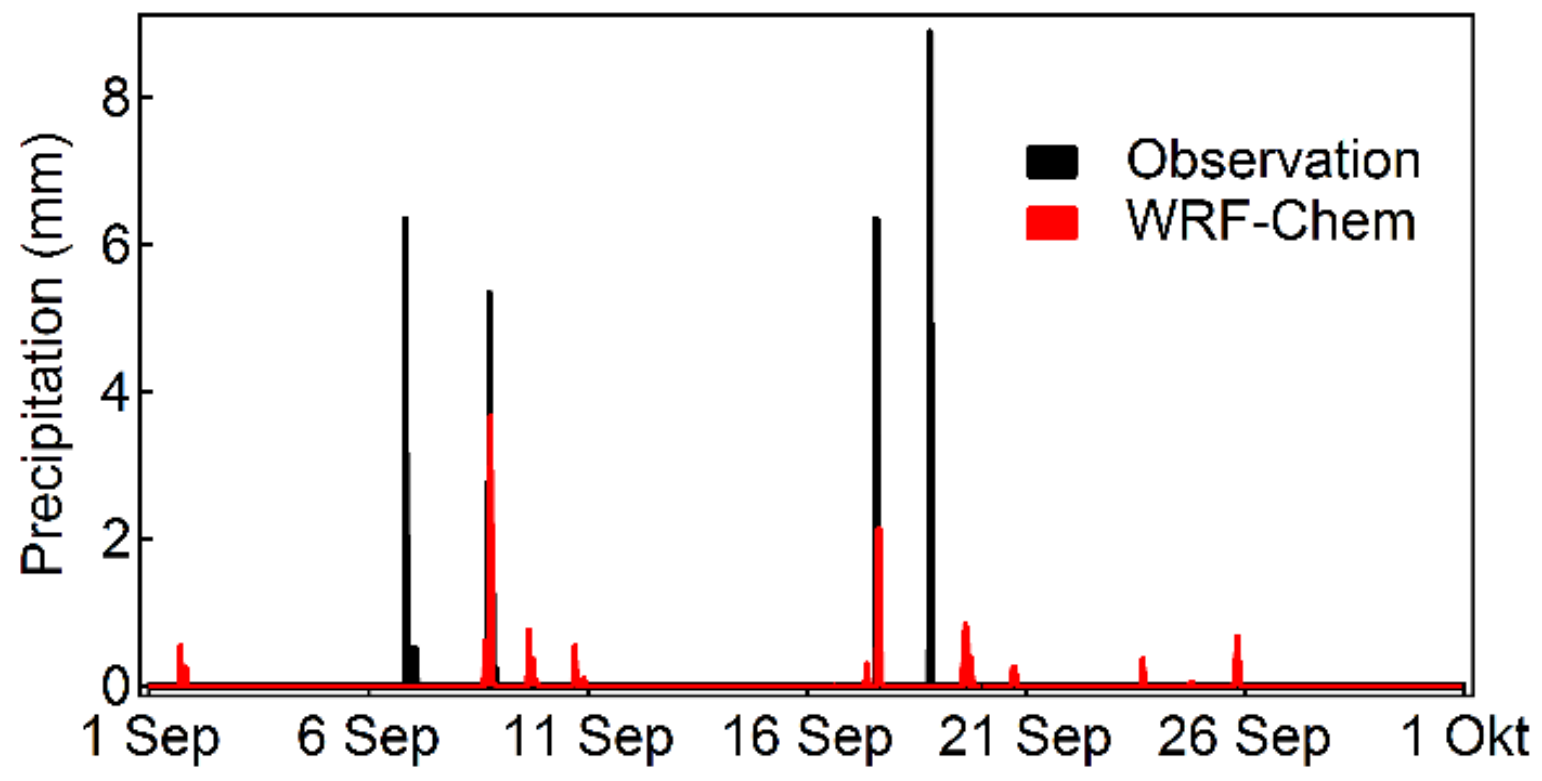

Figure S1. Time series of precipitation from observations at the ATTO site and WRF-Chem simulations during September 2014. 


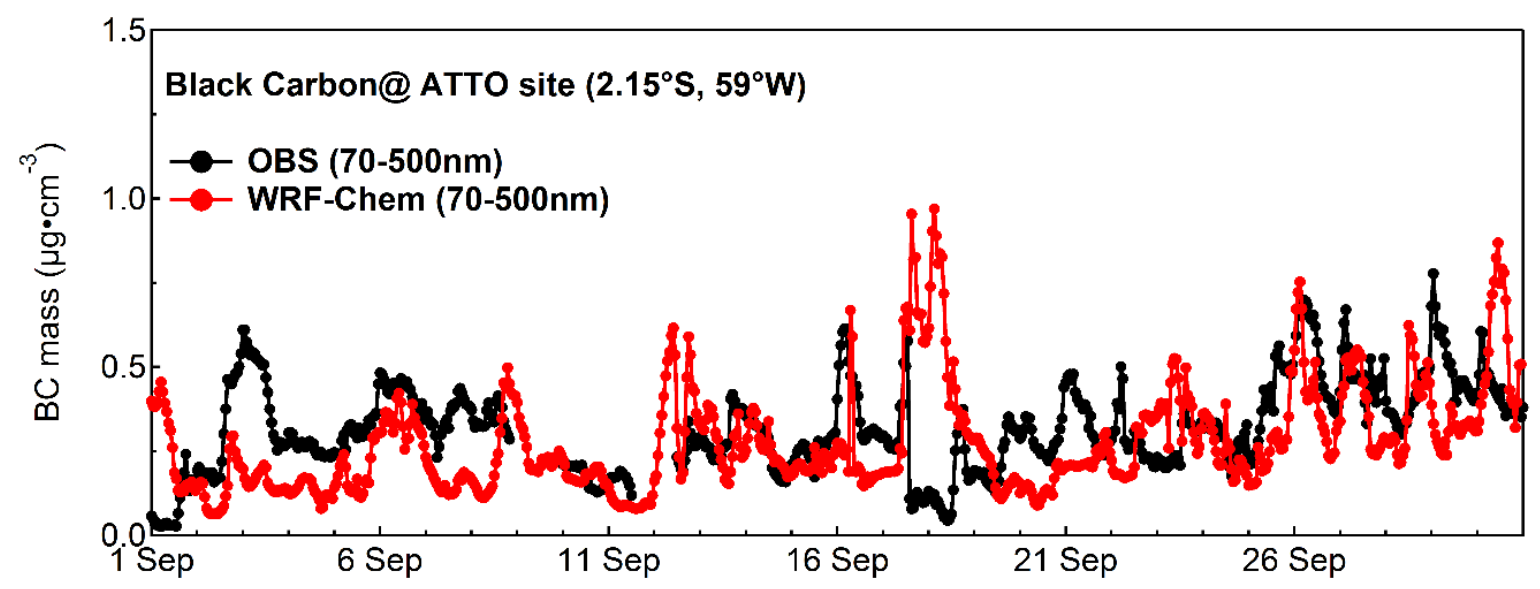

Figure S2. Time series of simulated and observed black carbon mass concentrations at the ATTO site. 

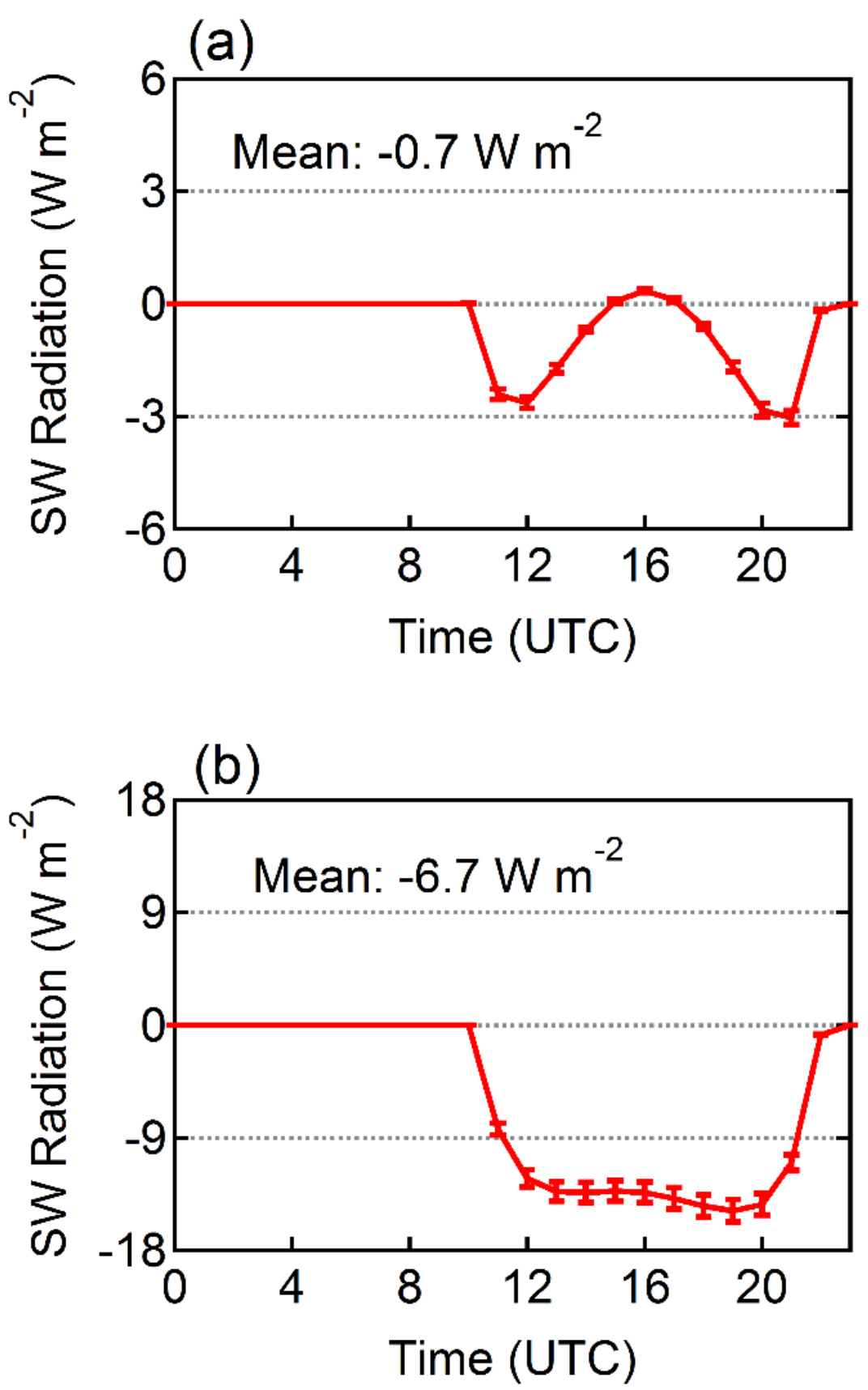

Figure S3. Diurnal variation of changes in clear-sky shortwave radiation at TOA (a) and at the surface (b) due to ARI in the EMIS1 emission scenario. Error bars denote the standard error. 

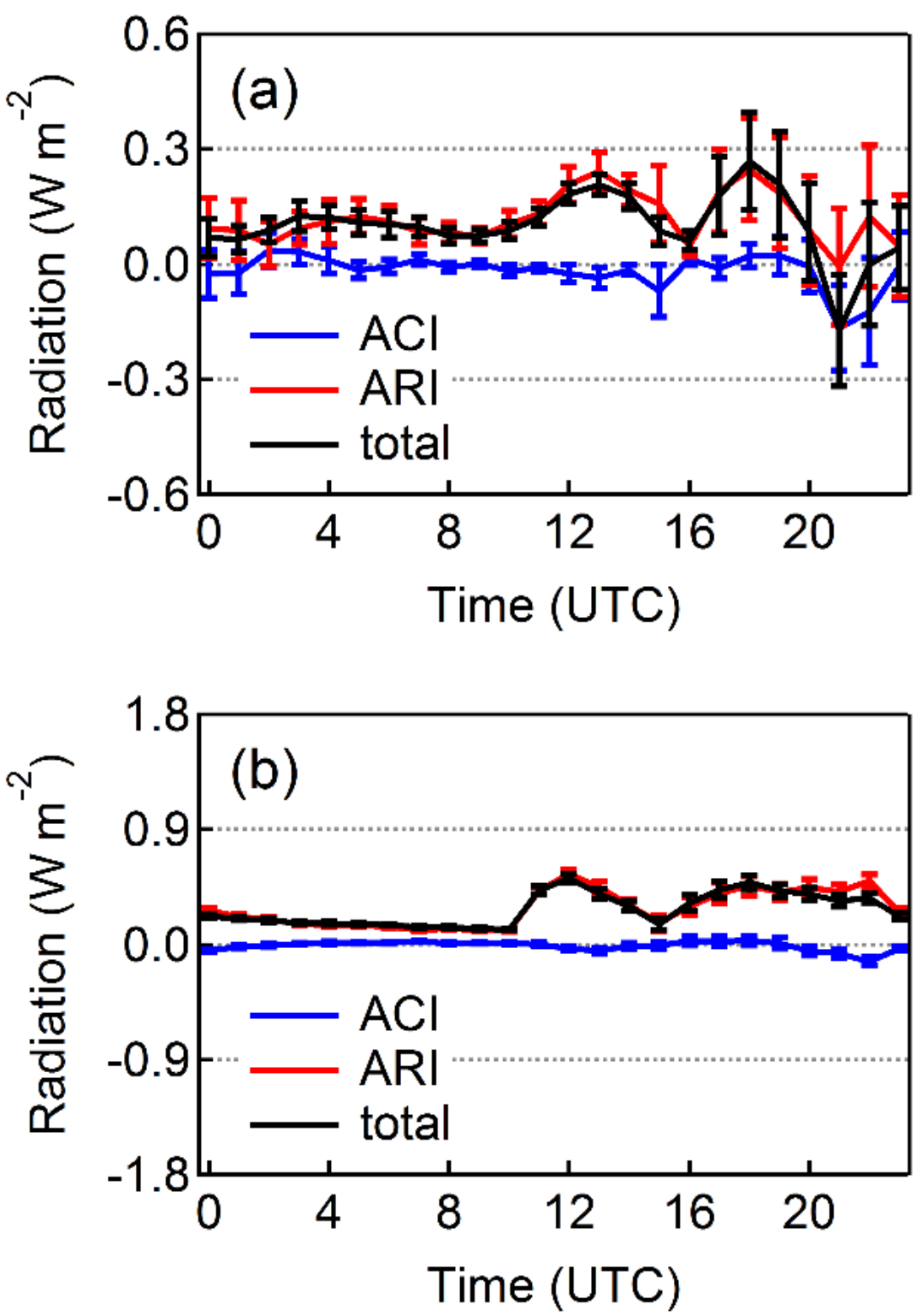

Figure S4. Diurnal variation of changes in all-sky longwave radiation at TOA (a) and at the surface (b) in the EMIS1 emission scenario. Error bars denote the standard error. 


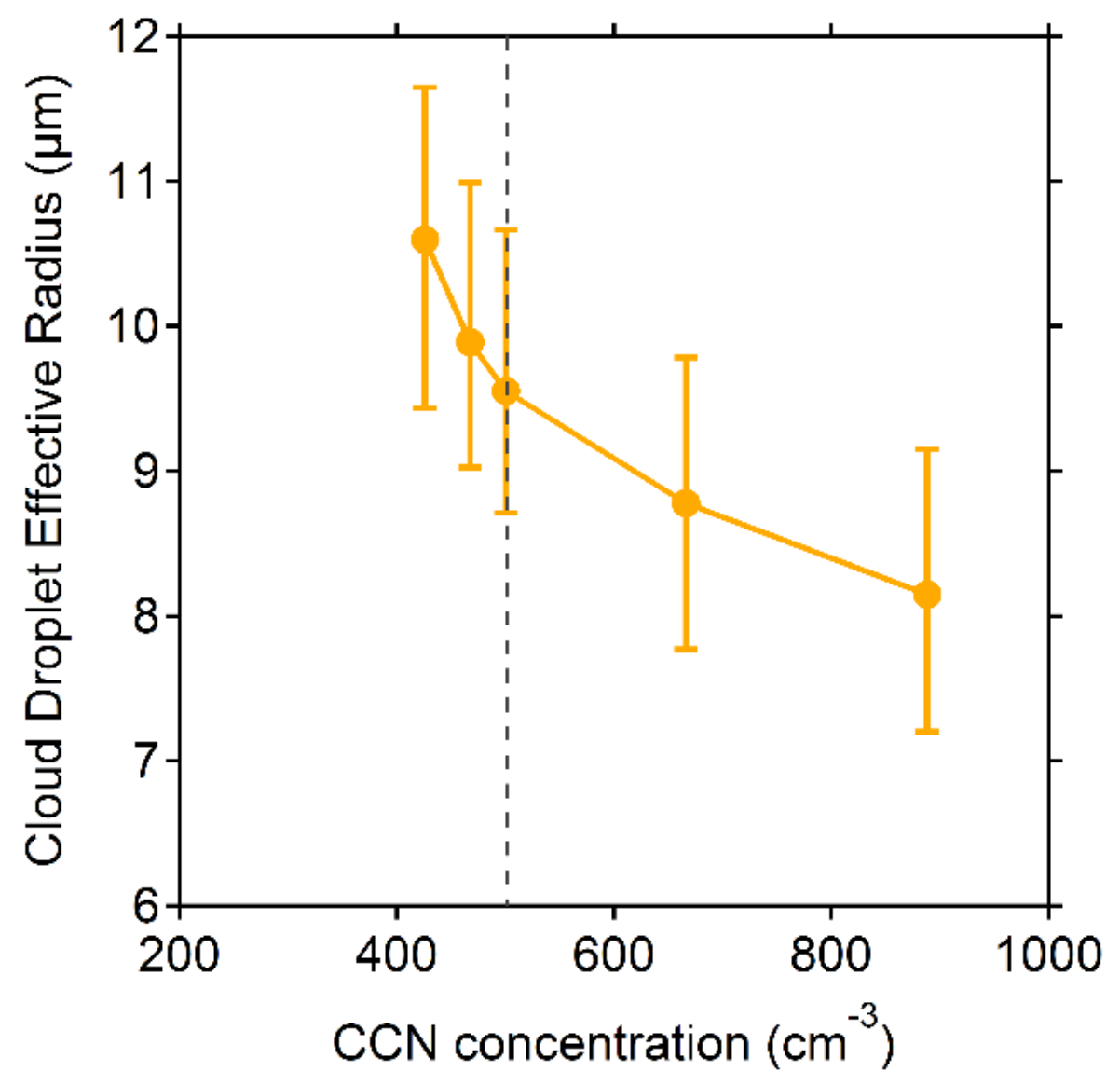

Figure S5. Relationship of monthly mean domain-averaged cloud droplet effective radius and cloud-base CCN concentrations for all emission scenarios derived from experiments of CCNR3 and PCNR3_EMISX. The dashed line indicates the EMIS1 scenario. Error bars represent the $25^{\text {th }}$ and $75^{\text {th }}$ percentiles of all domain-averaged data in each simulation. 

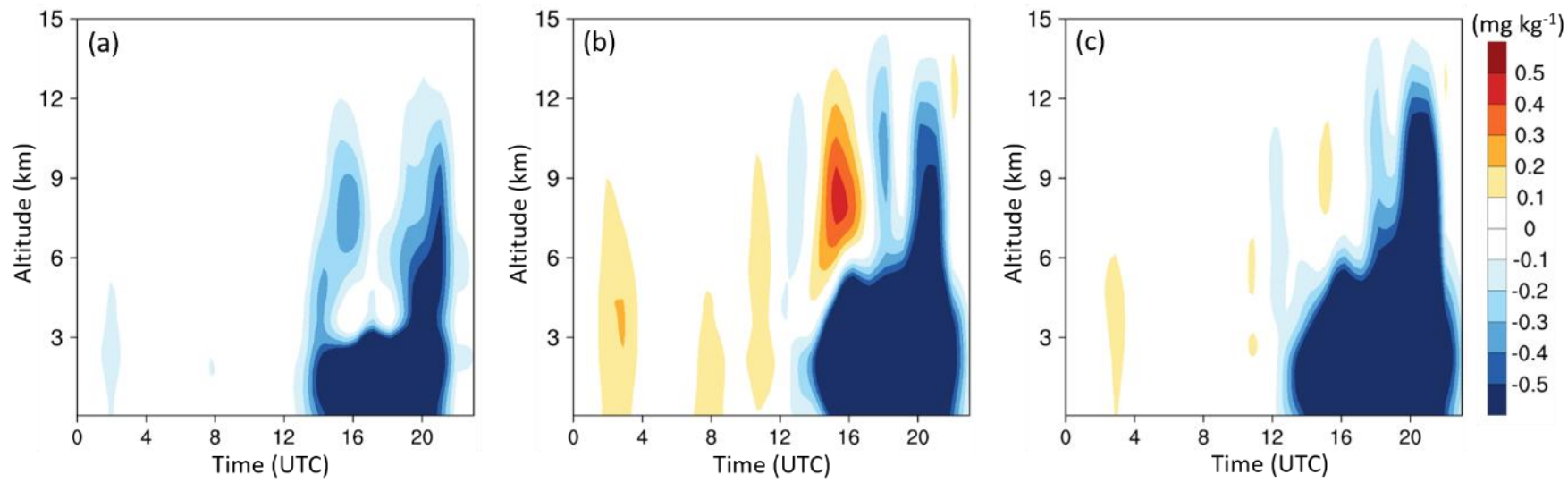

Figure S6. Diurnal variation of the vertical distribution of the domain-averaged difference in precipitating hydrometer (QRAIN+QSNOW+QGRAUP) concentrations caused by BB aerosols' ACI (a), ARI (b), and total effect (c) in the EMIS6 emission scenario. 

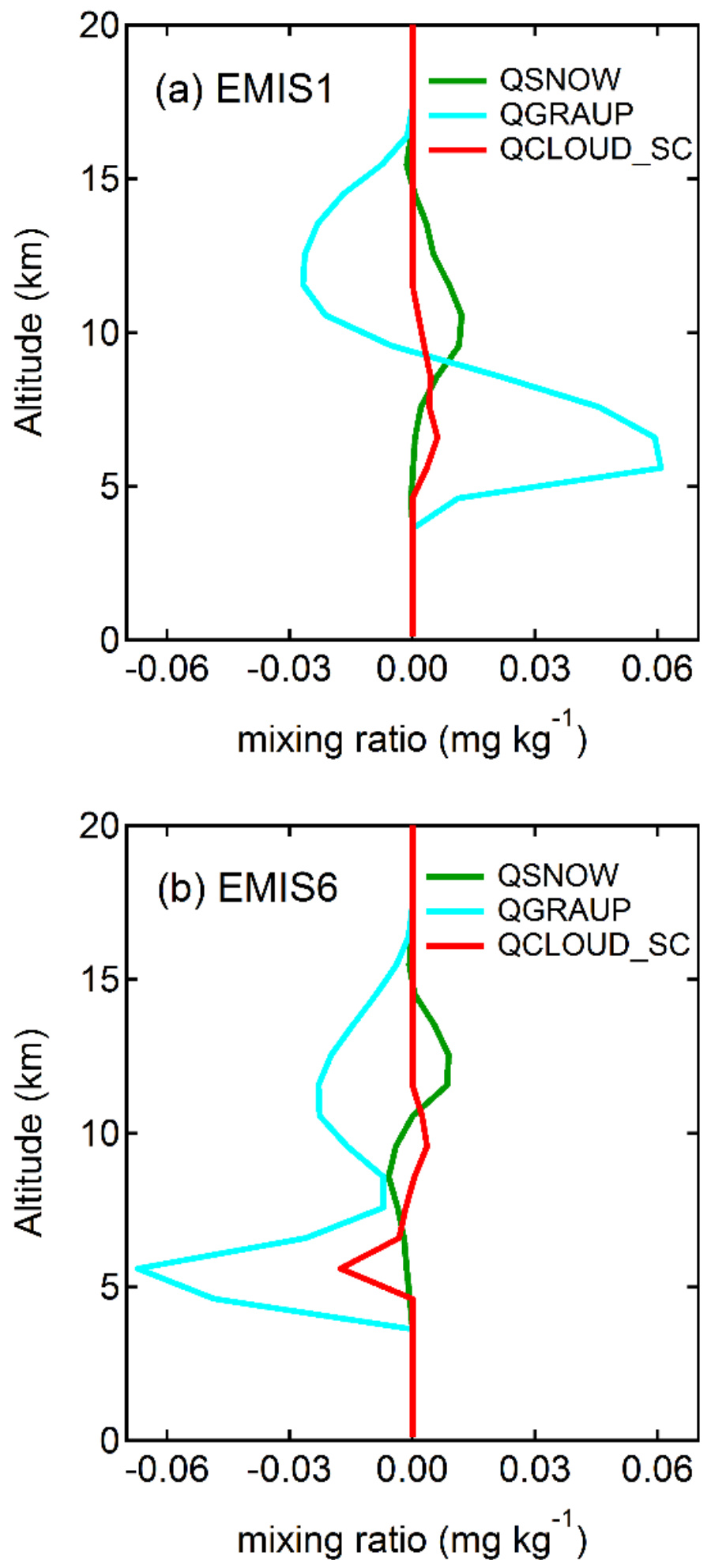

Figure S7. Profiles of ARI-induced changes in snow, graupel, and super-cooled cloud water mixing ratios for emission scenarios EMIS1 (a) and EMIS6 (b). 


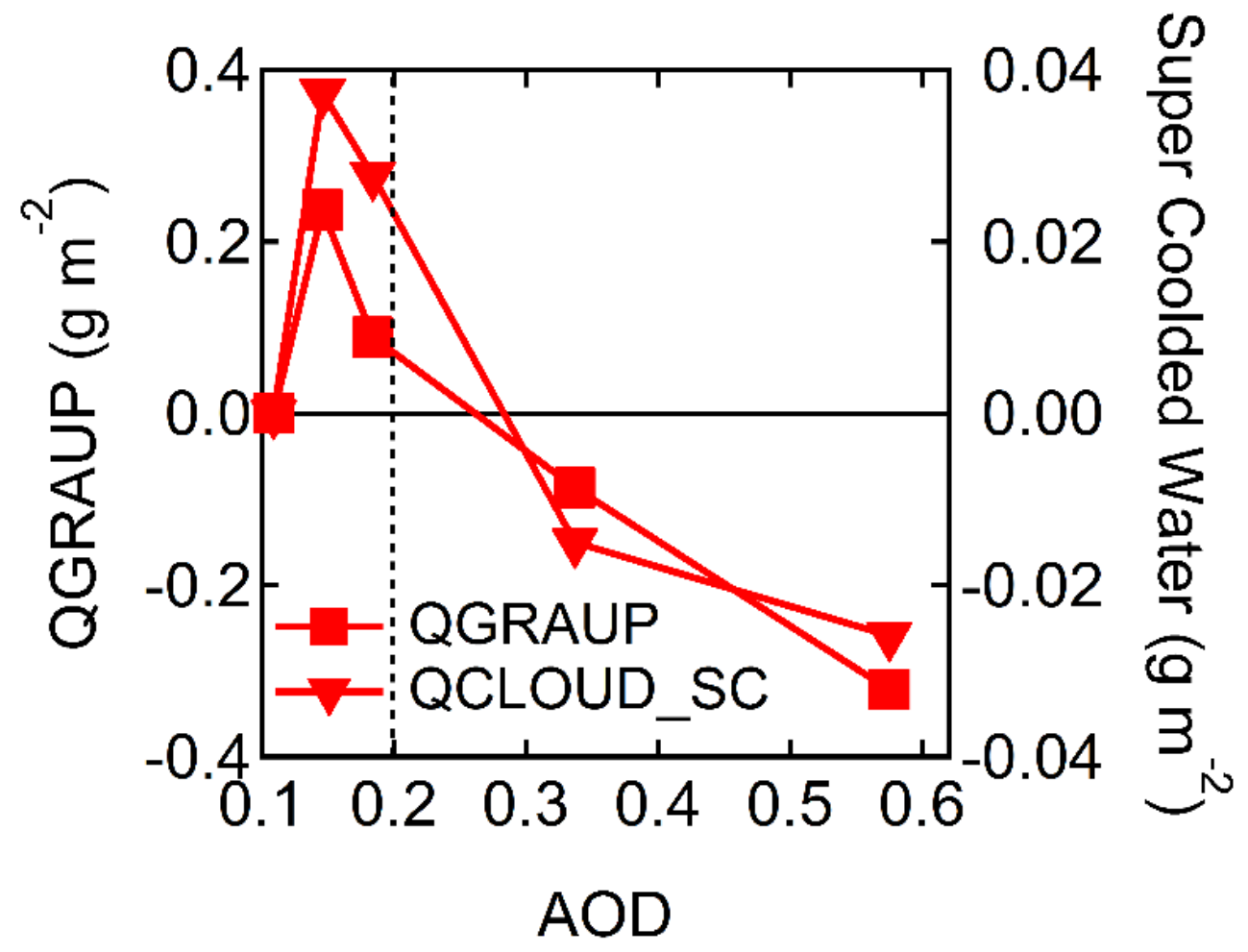

Figure S8. ARI-induced changes in column-integrated graupel and super-cooled cloud water content with increasing BB emission intensity (indicated by the domain-averaged AOD in each emission scenario). The vertical dotted line in each plot indicates the EMIS1 scenario. 